growing brain and used only when tumor recurrence has been demonstrated. After radical excision, the rate of recurrence was lowest, with a 10 year recurrence-free survival rate of $88 \%$. After subtotal removal, the recurrence-free survival rate, 10 yrs post-op, was 37\%; this rate was significantly higher (72\%) when subtotal removal was followed by irradiation, but deafness and severe neuropsychological and intellectual sequelae were frequent complications of irradiation. Post-operative mortality was low in pre-chiasmatic cases and high in retro-chiasmatic tumors. Surgical statistics may improve with newer techniques. (PierreKahn A et al. Traitement des craniopharyngiomes de l'enfant. Analyse retrospective de 50 observations. Arch Fr Pediatr Mars 1988;45:163-167).

COMMENT: The neuropsychological deficits ascribed to irradiation in this report may be explained in part by the location of the tumor. Cognitive defects have been correlated with frontal lobe abnormalities seen on MRI in 4 patients with craniopharyngioma (Stelling MW et al. Am J Dis Child 1986;140:710).

\title{
INEECTIOUS DISEASE
}

\section{TREATMENT OF AIDS ENCEPHALOPATHY}

A 3-year old boy who had acquired HIV infection transplacentally and developed AIDS encephalopathy is reported from the Depts of Paediatrics and Immunology, Newcastle General Hospital, Newcastle upon Tyne, England. During hemophilus influenza pneumonia at 26 months his speech regressed to expressive aphasia and he developed spastic diplegia with inability to walk. CT scan showed cerebral atrophy. CSF showed no cells and normal glucose and protein; IgG antibodies to HIV were increased. Treatment with intravenous gammaglobulin $300 \mathrm{mg} / \mathrm{kg}$ and oral zidovudine (RetrovirWellcome) $100 \mathrm{mg} / \mathrm{m}^{2} 4 \mathrm{x}$ daily every 4 weeks for 8 months led to considerable clinical improvement and an almost normal CT. Spasticity regressed allowing him to run unaided and his speech in single words became articulate. (Matthews $\mathrm{J}$ et al. AIDS encephalopathy with response to treatment. Arch Dis Child May 1988; 63:545-547).

COMMENT: AIDS encephalopathy may be acute and rapidly progressive (15\%), subacute but progressive (18\%), and static with cognitive deficits (28\%). A plateau course is apparent in many. The reported case was subacute in onset and without treatment further progression might have been expected. (See Ped Neur Briefs 1988;ㅁ:1).

\section{PSYCHOGENIC DISORDERS}

\section{HYSTERICAL GAIT}

In a study of the clinical features of conversion disorder in 52 children admitted to the Royal Alexandra Hospital for Children, Camperdown, New South Wales, Australia, hysterical gait disturbance was the main complaint in 71\%, and pain, paresthesia or anesthesia in 77\%. So called classical conversion symptoms such as blindness and globus were relatively rare. The disorder was rare below 8 years of age and girls outnumbered boys three to one. Spring and summer (Sept-Nov and Jan-Mar in Australia) accounted for $75 \%$ of admissions, coinciding with the end of year exams and the beginning of the new school year. Only 6 children had 